\title{
Network Reconfiguration for Loss Reduction with Distributed Generations Using PSO
}

\author{
Wardiah Mohd Dahalan \\ Department of Marine Electrical Engineering, \\ Universiti Kuala Lumpur Malaysian Institute of Marine \\ Engineering Technology \\ Perak, Malaysia \\ wardiah@mimet.unikl.edu.my
}

\author{
Hazlie Mokhlis \\ Department Electrical Engineering, Faculty of Engineering, \\ UM Power Energy Dedicated Advanced Centre \\ (UMPEDAC), Faculty of Engineering, \\ University of Malaya, \\ Kuala Lumpur, Malaysia \\ hazli@um.edu.my
}

\begin{abstract}
This paper presents an effective method based on Particle Swarm Optimization (PSO) to identify the switching operation plan for feeder reconfiguration and optimum value of DG size simultaneously. The main objective is to reduce the real power losses and improve the bus voltage profile in the system while satisfying all the distribution constraints. A method based on PSO algorithm to determine the minimum configuration is presented and their impact on the network real power losses and voltage profiles are investigated. To demonstrate the validity of the proposed algorithm, computer simulations are carried out on 33 bus systems and the results are presented and compare with the Genetic Algorithm (GA) method.
\end{abstract}

Keywords - Reconfiguration, Particle Swarm Optimization, Loss Reduction and Distributed Generation.

\section{I.}

\section{INTRODUCTION}

The increasing demand in the power system has posed a challenging task to power system engineers in maintaining a reliable and secure system economically. In the heavily loaded network, the load current drawn from the source would increase. This may lead to an increase in voltage drop and system losses. The performance of distribution system becomes inefficient due to the reduction in voltage magnitude and increase in distribution losses. Therefore, the operating cost will also increase. With this regard, changing environment of power systems design and operation have necessitated the need to consider active distribution network by incorporating Distributed Generation units (DGs) sources [1]. DGs are grid-connected or stand-alone electric generation units located within the electric distribution system at or near the end user. The integration of DGs in distribution system would lead to improving the voltage profile, reliability improvement such as service restoration and uninterruptible power supply and increase energy efficiency. Therefore, it is of crucial importance to study their impacts on distribution systems. The distribution feeder reconfiguration (DFR) is one of the most significant control schemes in the distribution networks which can be affected by the interconnection of DGs.
Generally, the DFR is defined as altering the topological structure of distribution feeders by changing the open/closed status of sectionalization and tie switches so that the power losses is minimized, and the constraints are met. In recent years, many researchers have investigated loss minimization in the area of network reconfiguration of distribution systems. The analysis from [2] has suggested of employing a method based on heuristic algorithm to determine the configuration of radial distribution networks, which finally led to loss minimization. Shirmohammadi et al. [3] also described heuristic optimization technique for the reconfiguration of distribution networks to decrease their resistive line losses. In another approach, V.Parada et. al. [4] proposed a solution procedure by employing simulated annealing (SA) to search an acceptable non-inferior solution. In [5], Sawa has proposed the new method in network reconfiguration that involves the discrete decimal mutant PSO and the fixed loop method. Jin et al [6] introduced a binary particle swam optimization based reconfiguration methodology for the distribution system. The objective of the reconfiguration was load balancing. The reconfiguration methodology proposed in that work can only be applied in the power system with radial configuration. Zhou, et al [7] put forward a heuristic reconfiguration methodology for the distribution system to reduce the operating cost in a real time operation environment. In that work, the operation cost in the power system is the power loss in the distribution system. The operation cost reduction in that work is based on the long term operation of the power system. Another heuristic search based reconfiguration algorithm was proposed by $\mathrm{Wu}$ et al [8]. In that work, the reconfiguration methodology was applied to the radial power system for service restoration, load balancing, and maintenance of the power system.

Although there are various methods [1]-[8] for network reconfiguration, the DGs effect in the network reconfiguration has not been considered widely by researchers. There are very few researchers who considered DFR with DG as mentioned in [9]-[11]. The method given in [9] applied a solution for network reconfiguration by employing the Tabu Search method to minimize the system power loss in the presence of distributed generators that cause reverse power flows and 
voltage variations. Meanwhile, Yuan et. al [10], have presented Ant Colony Algorithm (ACA) to achieve the minimum power loss and increment load balance factor of radial distribution networks with distributed generators. Ref. [11] introduced network reconfiguration techniques for loss reduction and voltage profile improvement under fault condition using a Tie Open Point Optimization (TOPO) connected with DG to determine the minimum configuration.

This paper proposes a network reconfiguration method for distribution network connected with DGs using the PSO algorithm. The proposed method is able to produce an optimum configuration in network distribution and at the same time yield the optimal size of DG and reduce power loss. The proposed PSO also improves convergence characteristics and less computation time as compared with GA method. The effectiveness of the methodology is demonstrated by a practical sized distribution system consisting of 33-bus system. The details of these algorithms are discussed in section II. Meanwhile, Section III shows the performance of this algorithm using standard test function. The simulation results in term of power loss and voltage profile are discussed in Section IV and finally the last section presents the conclusion of the study.

\section{PROBLEM FORMULATION}

The purpose of distribution network reconfiguration is to find a radial operating structure that minimizes the system power losses while satisfying operating constraints. Thus the problem can be formulated as follows [6].

$$
\operatorname{Min} P_{\text {losses }}=\sum_{i=1}^{n}\left|I_{i}\right|^{2} k_{i} R_{i} \quad i \in N
$$

Where is $I_{i}=$ current in branch $i, R_{i}=$ resistance of branch $i, N$ is the total number of branches and $k_{i}$ is the variable that represents the topology status of the branches $(1=$ close, $0=$ open).

\section{Subject to:}

a) Radial network constraint:

Distribution network should be composed of radial structure considering operational point view.

b) Node voltage constraint:

Voltage magnitude $V_{i}$ at each node must lie within their permissible ranges to maintain power quality

$$
V_{\min } \leq V_{b u s} \leq V_{\max }
$$

The standard minimum voltage used is 0.95 and maximum voltage is $1.05( \pm 5 \%)$. The process of works begins with the initial population.

c) Generator operation constraints:
All DG units are only allowed to operate within the acceptable limit where $p_{i}{ }^{\min }$ and $p_{i}{ }^{\max }$ are the lower and upper bound of DG output.

$$
p_{i}^{\min } \leq p_{g} \leq p_{i}^{\max }
$$

d) Feeder capability limits:

$$
\left|I_{k}\right| \leq I_{k}^{\max } k \in\{1,2,3, \ldots l\}
$$

where $I_{k}^{\max }=$ maximum current capability of branch $\mathrm{k}$.

- Radial configuration format.

- No load-point interruption

\section{FUNDAMENTAL PARTICLE SWARM OPTIMIZATION ALGORITHM (PSO)}

Particle Swarm Optimization is one of the heuristic methods used by researchers to solve many problems related to power systems. The basic idea of the PSO is based on the social behavior (foraging) of organisms such as fish (schooling) and bird (flocking) [20-21]. The birds or fish will move to the food in certain speed or position. Their movement will depend on their own experience and experience from other 'friends' in the group ( $P_{b e s t}$ and $\left.G_{b e s t}\right)$. The new velocity, $V_{j}^{k+1}$ and the new position, $X_{j}^{k+1}$ for the fish or birds are obtained using Eq.(5) and (6).

$$
\begin{aligned}
& V_{j}^{k+1}=\omega \times V_{j}^{k}+C_{1} \times \text { rand }_{1} \times\left(P_{\text {bestj }}^{k}-X_{j}^{k}\right)+C_{2} \times \text { rand }_{2} \\
& \times\left(G_{\text {best }}^{k}-X_{j}^{k}\right) \\
& X_{j}^{k+1}=X_{j}^{k}+V_{j}^{k+1}
\end{aligned}
$$

where $V_{j}^{k}$ is the velocity of particle $j$ in iteration $k, X_{j}^{k}$ is the position of particle $j$ in iteration $k$, rand 1 and $\operatorname{rand}_{2}$ are the random numbers between 0 and $1 . P_{b e s t j}^{k}$ is the best value of the fitness function that has been achieved by particle $j$ before iteration $k . G_{b e s t}^{k}$ is the best value of the fitness function that has been achieved so far by any particle. Constants $C_{1}$ and $C_{2}$ are weighting factors of the random acceleration terms which are usually set to 2.0. While low values allow particles to move away from the target region before they are pulled back, high values result in sharp movements toward the target region. The inertia weight $\omega$ is typically set according to the following equation:

$$
\omega(t+1)=\omega_{\max }-\frac{\omega_{\max }-\omega_{\min }}{t_{\max }} \times t
$$


In Eq.(7), $t_{\max }$ is the maximum number of iterations and $t$ is the current iteration number. $\omega_{\max }$ and $\omega_{\min }$ are maximum and minimum of the inertia weights, respectively. The process of implementation of PSO algorithm is as follows:

Step 1: The input data including network configuration, line impedance and status of DGs and switches are to be read.

Step 2: Setup the set of parameters of PSO such as, number of particles $N$, weighting factors and $C_{1}, C_{2}$. The initial population is determined by selecting the tie switches and DG size randomly from the set of the original population. The variable for tie switches represented by $S$ and as for DG size is represented by $p_{g}$. The proposed particles can be written as:

$$
X_{\text {particle }}=\left\{S_{1}, S_{2}, \ldots S_{\beta}, P_{g 1}, P_{g 2}, \ldots . P_{g \alpha}\right\}
$$

where $\beta$ is the number of tie line and $\alpha$ is the number of DG.

Step 3: Calculate the power loss using distribution load flow based on the Newton - Raphson method.

Step 4: Randomly generates an initial population (array) of particles with random positions and velocities on dimension in the solution space. Set the iteration counter $k=0$.

Step 5: For each particle if the bus voltage is within the limits, calculate the total loss using distribution load flow. Otherwise, that particle is infeasible.

Step 6: Record and update the best values.

The two best values are recorded in the searching process. Each particle keeps track of its coordinate in the solution space that is associated with the best solution it has reached so far. This value is recorded as $P_{\text {best }}$. Another best value to be recorded is $G_{\text {best }}$ , which is the overall best value obtained so far by any particle. $P_{\text {best }}$ and $G_{\text {best }}$ are the generations of switches, Dg sizes and power loss. This step also updates $P_{b e s t}$ and $G_{b e s t}$. At first, we compare the fitness of each particle with its $P_{b e s t}$. If the current solution is better than its $P_{b e s t}$, then replace $P_{b e s t}$ by the current solution then, the fitness of all particles is compared with $G_{\text {best }}$. If the fitness of any particle is better than $G_{\text {best }}$, then replace $G_{\text {best }}$.

Step 7: Update the velocity and position of the particles. Eq.(5) is applied to update the velocity of the particles. The velocity of a particle represents a movement of the switches. Meanwhile, Eq.(6) is applied to update the position of the particles.

Step 8: End conditions.

Check the end condition, if it is reached the algorithm stops, otherwise, repeat steps 3-7 until the end conditions are satisfied.
In this work, we only determined the optimal size of DG while the location of DG is fixed [22]. DG location in the network is fixed as a controlled measure in order to observe the responding changes of DG sizing. Furthermore, the DG location in practical is also depends on the suitability of the area.

\section{CASE STUDIES}

The test system for the case study consisting of the standard IEEE 33-bus radial distribution system is shown in Fig.1. The system consists of one feeder, 32 normally closed tie line and five normally open tie lines (dotted line) and located on branch No. 33, 34, 35, 36 and 37. The system load is assumed to be constant and Sbase $=100 \mathrm{MVA}$ and Vbase $=12.66 \mathrm{KV}$. The line and load data details can be referred in [10]. The total load on the system is $3715 \mathrm{~kW}$ and $2300 \mathrm{kVAr}$.

The maximum active output of DG in this study is set to $5 \mathrm{MW}$. While, the size of the population for test systems is 50 . The convergence value is taken as 0.0001 . The minimum and maximum voltages are set at 0.95 and 1.05 p.u.respectively. All calculations for this method are carried out in the per-unit system. Four cases are considered:

Case 1: The system is without distributed generation and feeder reconfiguration (initial)

Case 2: The same as case 1 except that the feeders can be reconfigured by the available sectionalizing switched and the tie switches.

Case 3: The same as case 1 except that there is, four DGs unit is installed and placed at bus number $6,12,25$ and 32 respectively .

Case 4: The same as case 3 but with feeder reconfiguration.

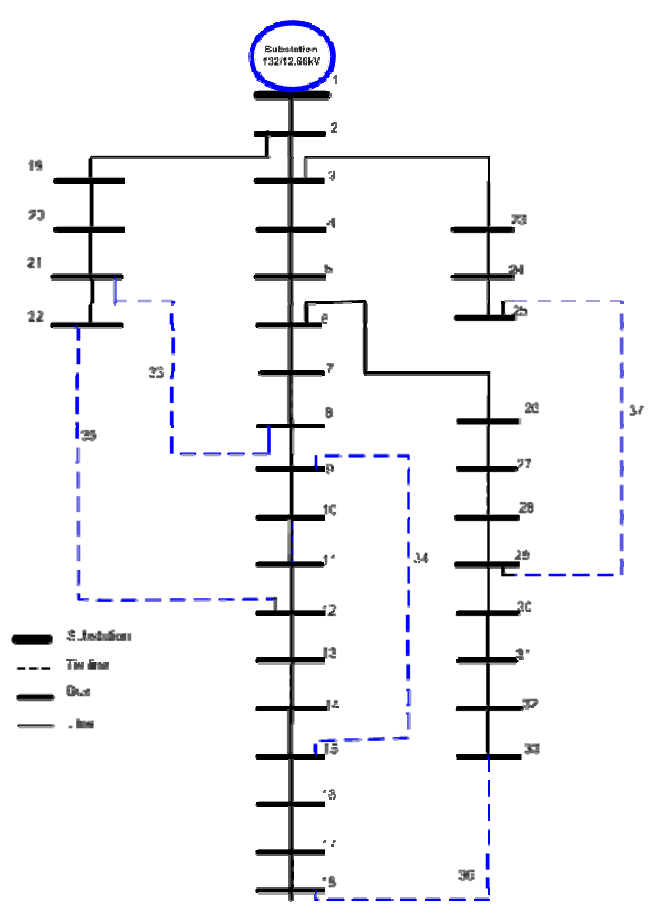

Figure 1. Initial configuration of the 33 bus radial distribution system 


\section{RESULTS AND DISCUSSION}

\section{V.1 Impact on Power Losses}

After this simulation is executed many times by using MATLAB software, only the minimum power loss with optimal DG size is selected.The results obtained consists of the five opened switches, total power loss and four optimal DG sizing. The numerical results for the four cases are summarized in Table I. The results show the performance of GA and PSO when tested using 33-bus distribution system. It is noticed a considerable decrease in the power loss values when the DG is placed in the distribution system. It is confirmed from case 3 that the DG helps to reduce the power loss after reconfiguration from $202.70 \mathrm{~kW}$ to $164 \mathrm{~kW}$, or $17.7 \%$ of the reconfigurations without DG.

TABLE I. RESUlts OF CASE StUdy

\begin{tabular}{|c|c|c|c|c|c|c|}
\hline Case & $\begin{array}{c}\text { Case 1 } \\
\text { (Initial) }\end{array}$ & \multicolumn{2}{|c|}{$\begin{array}{c}\text { Case 2 } \\
\text { (Recon ) }\end{array}$} & $\begin{array}{c}\text { Case 3 } \\
\text { (DG) }\end{array}$ & \multicolumn{2}{c|}{$\begin{array}{c}\text { Case 4 } \\
\text { (Recon + DG) }\end{array}$} \\
\hline Method & - & PSO & GA & - & PSO & GA \\
\hline $\begin{array}{c}\text { Opened } \\
\text { Switch }\end{array}$ & $\begin{array}{c}333435 \\
3637\end{array}$ & $\begin{array}{c}710 \\
2814 \\
32\end{array}$ & $\begin{array}{c}7914 \\
2832\end{array}$ & $\begin{array}{c}3334 \\
3536\end{array}$ & $\begin{array}{c}7810 \\
28\end{array}$ & $\begin{array}{c}7914 \\
2832\end{array}$ \\
\hline $\begin{array}{c}\text { Power } \\
\text { Loss(kW) }\end{array}$ & 202.70 & 126.4 & 135.3 & 164.0 & 92.3 & 112.4 \\
\hline $\begin{array}{c}\text { Loss } \\
\text { reduction } \\
\text { (\%) }\end{array}$ & - & 37.6 & 32.4 & 17.7 & 51.4 & 44.5 \\
\hline $\begin{array}{c}\text { CPU time } \\
\text { (s) }\end{array}$ & - & 16.2 & 36 & - & 13.4 & 30 \\
\hline $\begin{array}{c}\text { No. of } \\
\text { Iterations }\end{array}$ & - & $88^{\text {th }}$ & $130^{\text {th }}$ & - & $74^{\text {th }}$ & $121^{\text {th }}$ \\
\hline
\end{tabular}

In case 4 , by applying reconfiguration with DG installation in the PSO method, the amount of power loss is improved from $126.4 \mathrm{~kW}$ to $92.3 \mathrm{~kW}$ which is about $34.1 \mathrm{~kW}$. But the same application done on the GA method has given lower improvement of $22.9 \mathrm{~kW}(135.3 \mathrm{~kW}$ to $112.4 \mathrm{~kW})$. Thus, the proposed PSO method in this paper has improved greater power loss as compared to GA method. In addition, the reading of power loss from PSO method after reconfiguration with DG in case 4 is only $92.3 \mathrm{~kW}$ as compared to the GA method which gives $112.4 \mathrm{~kW}$, a different of $20.1 \mathrm{~kW}$. From the perspective of power losses, PSO impacted positively in the analyzed distribution network, achieving $51.4 \%$ improvement. If we compare the CPU time, the computing time of the PSO method is only 13.4 seconds compared to the GA method which requires 30 seconds. Hence, PSO method is 16.6 seconds faster than GA method.

TABLE II. SIZES OF DG FOR PSO AND GA METHODS

\begin{tabular}{|c|c|c|c|c|c|c|}
\hline \multirow{2}{*}{$\begin{array}{c}\text { No. } \\
\text { of }\end{array}$} & \multirow{2}{*}{$\begin{array}{c}\text { Location } \\
\text { (Bus) }\end{array}$} & \multicolumn{5}{|c|}{ DG sizes } \\
\cline { 3 - 7 } DG & & & \multicolumn{2}{|c|}{ Case 3 (MW) } & \multicolumn{2}{c|}{ Case 4 (MW) } \\
\hline DG1 & 6 & 1.865 & 1.6055 & 1.6675 & 1.6725 & 1.7454 \\
\hline DG2 & 12 & 0.5757 & 0.4836 & 0.4903 & 0.3798 & 0.4808 \\
\hline DG3 & 25 & 0.7824 & 0.6900 & 0.8001 & 0.6255 & 0.7890 \\
\hline DG4 & 32 & 0.9058 & 0.7055 & 0.8599 & 0.6560 & 0.8585 \\
\hline
\end{tabular}

Based on case 4, four DG are installed at different locations which has been fixed earlier. Once the program is run, the sizes of DG will vary automatically between the range of $0 \mathrm{MW}-5 \mathrm{MW}$ until it reaches the optimal values. It can be seen from the Table II that the optimum DG size for PSO is at $1.6725 \mathrm{MW}, 0.3798 \mathrm{MW}, 0.6255 \mathrm{MW}$ and $0.6560 \mathrm{MW}$. In fact, the size of DG in case 3 is slightly higher than case 4 due to the absence of reconfiguration. The analysis also indicates that the maximum saving is achieved when the four DG are placed at bus number $6,12,25$ and 32 as shown on the diagram. The schematic diagram of the system after reconfiguration with DG installation is shown in Fig. 2. Meanwhile, the maximum iteration to reach the optimal value is requires 121 for GA and only requires 74 iterations for the proposed method to converge as illustrated in Fig. 3 and 4 for the best solution. This shows that the proposed method is capable of solving problems faster during the simulation and converge them within a short period of time as compared to GA method.

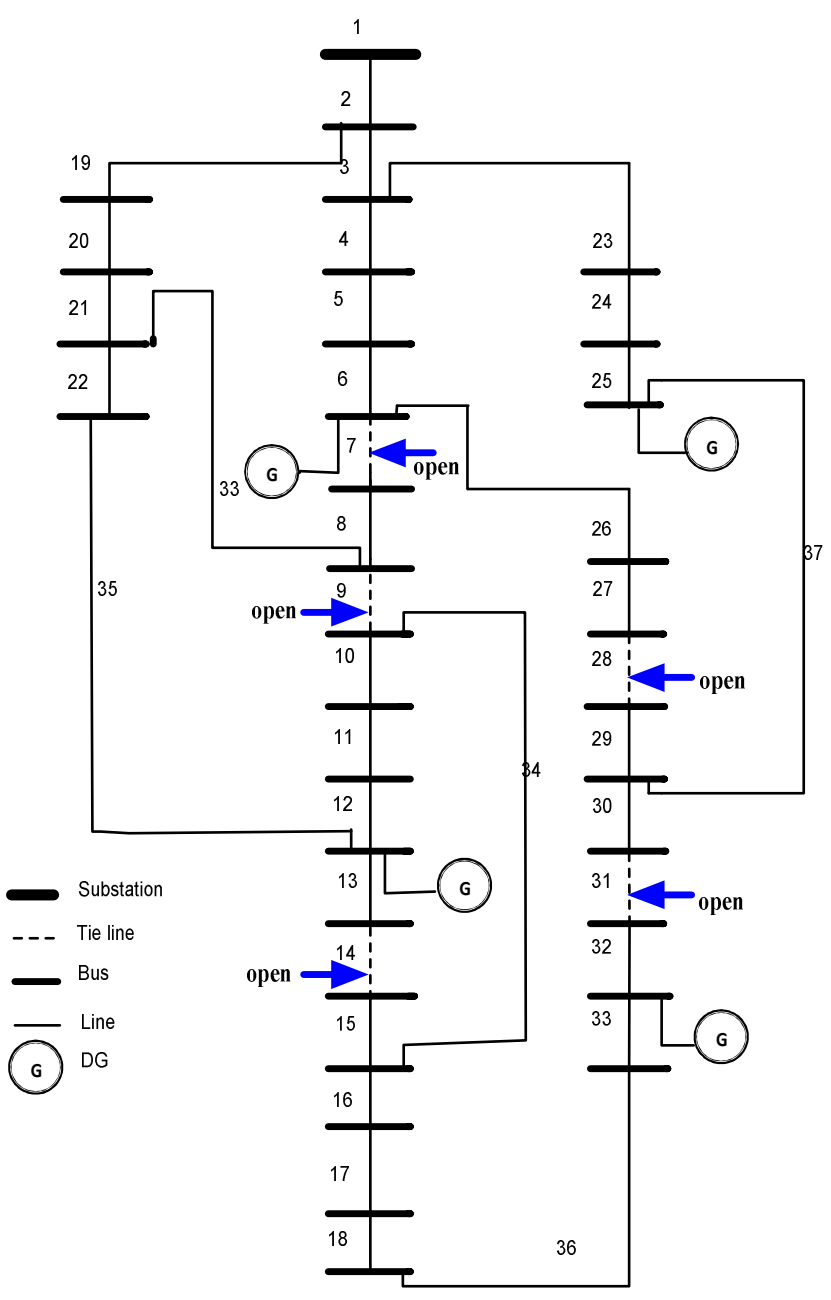

Figure 2. Network Reconfiguration with 4 DGs of 33-bus system Total Power Loss $=92.3 \mathrm{~kW}$ 


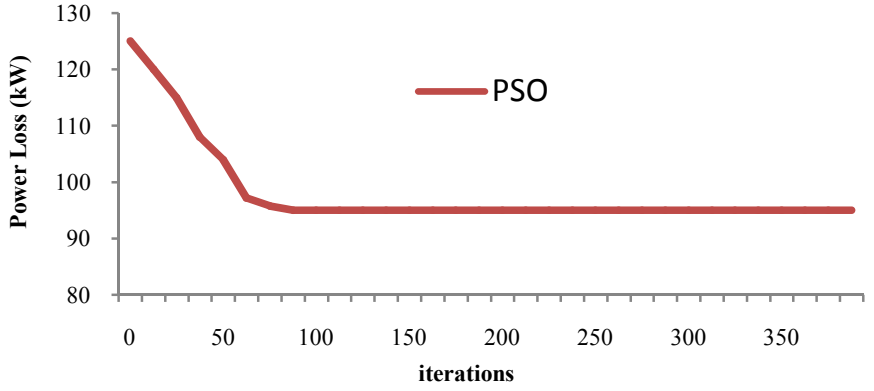

Figure 3. Convergence performance of PSO for the best solution

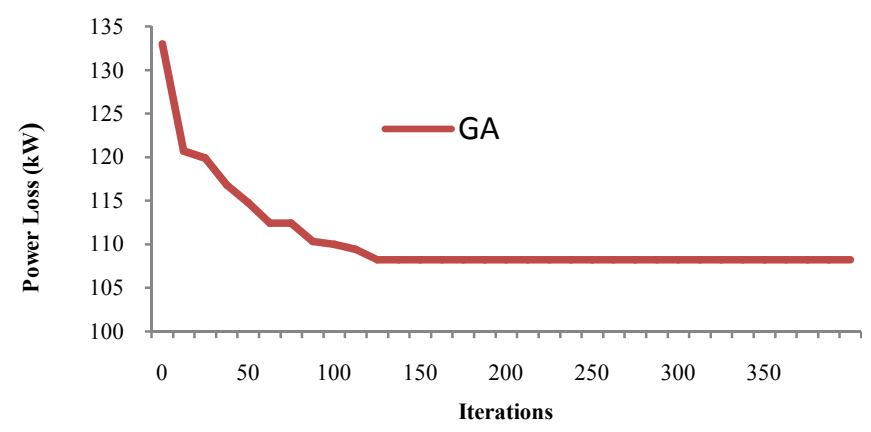

Figure 4. Convergence performance of GA for the best solution.

\section{V.2 Impact on Voltage}

The proposed method does not only give the lowest power losses, but also improves the overall voltage profile of the network reconfiguration. Fig.5 illustrated the results of case 2 without DG on voltage profile achieved by the two of the algorithms. The minimum voltage profile is equal $0.7746 \mathrm{p} . \mathrm{u}$ and then being raised to $0.8939 \mathrm{p} . \mathrm{u}$ after reconfiguration.

Meanwhile, Fig.6 depicted the results of case 4 with reconfiguration and $\mathrm{DG}$ on voltage profile improvement achieved by the proposed algorithm. In this case, there are slightly improvements of $6 \%$ on the voltage value at bus 13 till bus 16 . While, the voltage improvement obviously between bus 25 till bus 29 is about $12 \%$. However, the minimum voltage is equal $0.9430 \mathrm{p}$.u before reconfiguration and then being raised to $0.9772 \mathrm{p} . \mathrm{u}$ after reconfiguration. The rest of the bus has almost the same value.

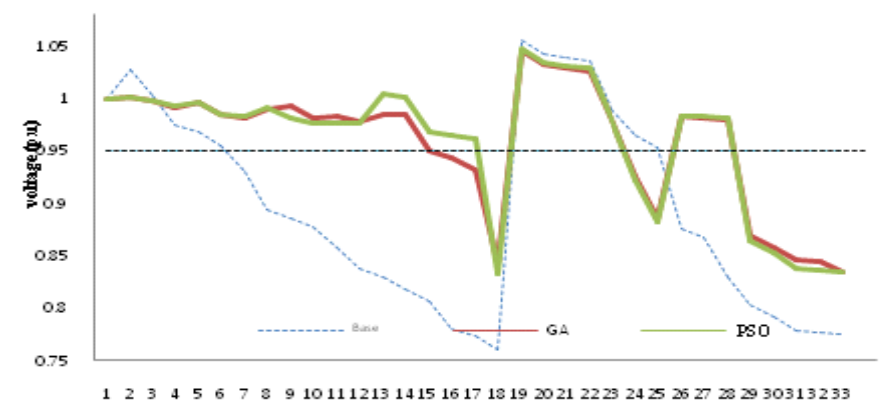

Bus nomber

Figure 5. Performance of voltage profile for 33 bus radial distribution system (case 2)

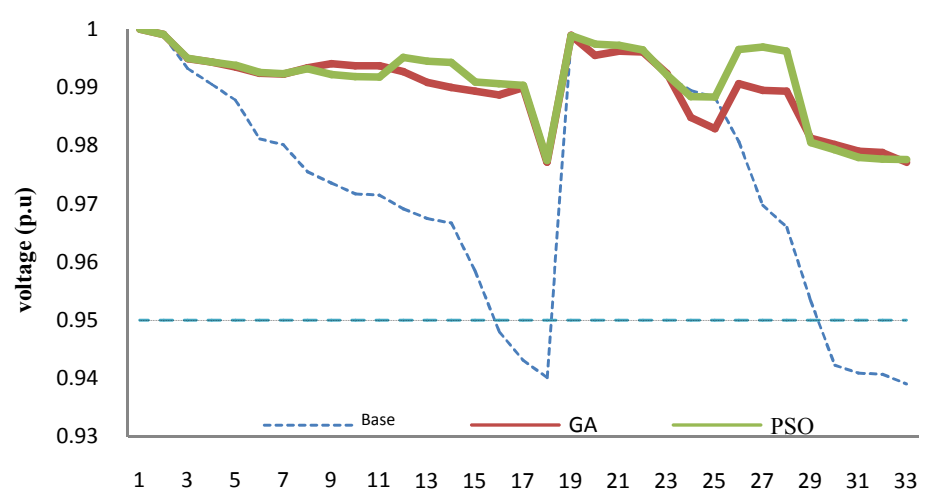

Bus number

Figure 6. Performance of voltage profile for 33 bus radial distribution system (case 4)

Fig.7 illustrates the relationship between power loss and DG with two proposed methods. The PSO shows a great difference after reconfiguration with DG. Since the PSO gives the fastest solution compared to others and its performance is better than traditional methods, it can be concluded that PSO is a superior method in reconfiguration with DG process.

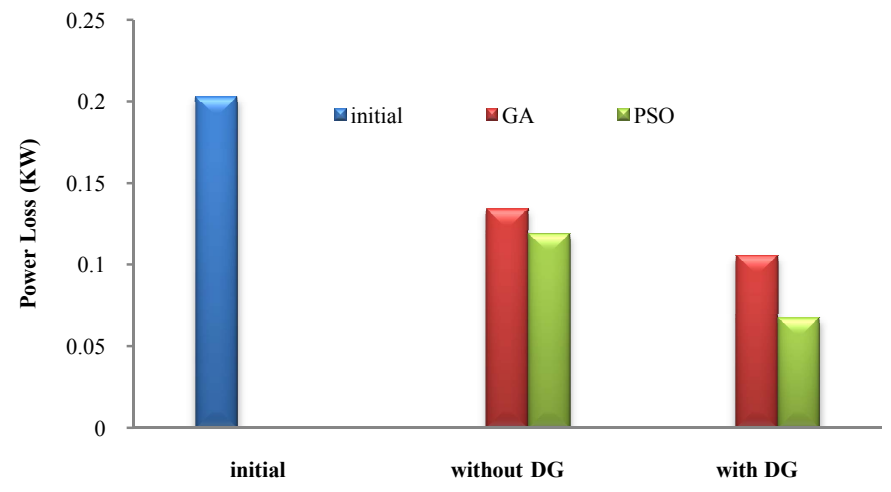

Figure 7. Comparison of power losses between GA and PSO

\section{CONCLUSION}

PSO technique has been developed in this paper with presence of distributed generators for reconfiguration of the distribution system. The main objective of this method is to reduce the real power losses by turning on/off the tie line and determine the optimum value of DG size simultaneously on the distribution network reconfiguration. A 33-bus distribution system with four distributed generation is used to demonstrate the effectiveness of the proposed technique. In this paper, four cases are considered as explained in section IV. The results of the proposed algorithm are compared with GA method.

From the analysis and simulation of the results, the overall perspectives between the two methods show that the PSO result surpasses GA in this application. PSO has shown tremendous improvement in term of processing time, number of iterations to reach the optimal value of power losses and the optimum value of DG sizing. From the simulation results 
indicated that the optimal on/off patterns of the tie line can be identified which give the minimum power loss while keeping bus voltage magnitudes within the acceptable limits. Based on these reasons, it is strongly expected that PSO is capable of solving large-scale problems arose in network reconfiguration as compared to the existing methods.

\section{REFERENCES}

[1] K. Nara, A. Shiose, M. Kitagawoa, and T. Ishihara, "Implementation of Genetic Algorithm for Distribution Systems Loss Minimum Reconfiguration", IEEE Transactions on Power Systems, vol. 7, no. 3, Aug. 1992, p. 1044-1051.

[2] S. Civanlar, J.J. Grainger, H. Yin, S.S.H. Lee, "Distribution feeder reconfiguration for loss reduction", IEEE Trans. Power Del. 3 (3) (1988) $1217-1223$

[3] D. Shirmohammadi, H.W. Hong, "Reconfiguration of electric distribution networks for resistive line loss reduction", IEEE Trans.Power Syst. 4 (1) (1989) 1492-1498.

[4] E. Lopez, h. Opaso., "Online reconfiguration considering the variability deman", applications to real networks, IEEE Trans. Power Syst.19 (1) (2004) 549-553.

[5] T.Sawa, "Radial Network Reconfiguration Method in Distribution System using Mutation Particle Swarm Optimization" IEEE Burcharest Power Tech Conference, June $28^{\text {th }}$, Romania.

[6] X. Jin, J. Zhao, Y. Sun, K. Li, B. Zhang, "Distribution Network Reconfiguration for Load Balancing using Binary Particle Swarm Optimization", International Conference on Power System Technology, vol. 1, no. 1, Nov. 2004, pp. 507-510

[7] Zhou, Q.; Shirmohammadi, D. and Liu, W.-H. E., "Distribution Feeder Reconfiguration for Operation Cost Reduction", IEEE Transactions on Power Systems, Vol. 12, No. 2, May 1997, pp. 730-735

[8] Wu, J.S.; Tomsovic, K.L. and Chen, C.S., "A Heuristic Search Approach to Feeder Switching Operations for Overload, Faults, Unbalanced Flow and Maintenance", IEEE Transactions on Power Delivery, Vol. 6, No. 4, Oct. 1991, pp. 1579-1586

[9] I.Z. Zhu, "Optimal reconfiguration of electrical distribution networks using the refined genetic algorithm", Elect. Power Syst. Res. 62(2002) $37-42$.

[10] Y.C.Huang, "Enhanced genetic algorithm-based fuzzy multi objective approach to distribution network reconfiguration", Proc. Inst .Elect. Eng. 149 (5) (2002) 615-620.

[11] Ching-Tzong Su, Chung-Fu Chang and Ji-Pyng Chiou, "Distribution Network Reconfiguration for Loss Reduction by Ant Colony Search Algorithm Electric Power Systems Research, Vol. 75, No. 2-3, pp. 190199,August 2005

[12] S.Ching-Tzong, C. Lee, "Network reconfiguration of distribution systems using improved mixed-integer hybrid differential evolution", IEEE Trans. Power Del. 18 (3) (2003) 1022-1027.

[13] N. Rugthai Charoencheep and S. Sirisumrannukul "Feeder Reconfiguration for Loss Reduction in Distribution System with Distributed Generators by Tabu Search", GMSARN International Journal 3 (2009) $47-54$.

[14] Yuan-Kang Wu, Chin-Yin Lee, Le-Chang Liu, and Shao-Hong Tsai. "Study of Reconfiguration for the Distribution System With Distributed Generators", IEEE transactions on Power Delivery, Vol. 25, No.3,July 2010.

[15] Z.M.Yasin, T.K.A. Rahman, "Network Reconfiguration in a Power Distribution System under Fault Condition with the Presence of Distributed Generation", International Conference on Energy and Environment 2006 (ICEE 2006)

[16] M.Oliveria, L. Ochoa, "Network Reconfiguration and loss allocation for distribution systems with distributed generation", IEEE/PES Trans. Distribution. Conference .Expos. (2004) 206-211.

[17] Sivanagaraju, S., Srikanth, Y., and Jagadish Babu, E. 2006, "An efficient genetic algorithm for loss minimum distribution system reconfiguration", Electric Power Components and Systems, 34: 249$258,2006$.

[18] H. Kim, Y. Ko, "Artificial neural network based feeder reconfiguration for loss reduction in distribution systems", IEEE Trans. Power Del. 8 (3) (1993) 1356-1367
[19] A. M. El-Zonkoly, Optimal placement of multi-distributed generation units including different load models using particle swarm optimization, IET Generation Transmission \& Distribution, vol. 5, no. 7, July 2011, pp. 760-771.

[20] M. H. Moradi and M. Abedini,A combination of genetic algorithm and particle swarm optimization for optimal DG location and sizing in distribution systems,International Journal of Electrical Power \& Energy Systems, vol. 34, no. 1, Jan. 2012, pp. 66-74.

[21] Lalitha M. Padma, Reddy V. C. Veera,Usha V., Reddy N. Sivarami, Optimal DG Placement for Minimum Real Power Loss in Radial Distribution System using PSO, ARPN Journal of Engineering and Applied Sciences 2010, Vol. 5, No. 4, pp. 30-37.

[22] A. Merlin, H. Back, "Search for a minimal-loss operating spanning tree configuration in an urban power distribution system", Proceedings of the Fifth Power System Computation Conference, Cambridge, UK, 1975, pp. 1-18. 